\title{
Jornada noturna
}

\author{
Night working shift
}

\author{
DIMAICON CIMA LIMA \\ JONATHAN VARGAS FIGUEIREDO ${ }^{b}$
}

\section{RESUMO}

A jornada de trabalho, tópico de abordagem desta revista, pode ser caracterizada como o período diário (diurno ou noturno) durante o qual o trabalhador está a disposição - subordinado ao seu empregador. Dentro desta ramificação do estudo do direito do trabalho, há a jornada de trabalho noturna, tema do presente artigo, que leva em consideração o tempo de serviço exercido durante a noite, especificamente determinado pela legislação, e as suas consequências dentro do ordenamento jurídico pátrio. De maneira a acompanhar o intenso estudo acadêmico da jornada noturna pelos campos das ciências humanas e sociais - Antropologia, Sociologia, Psicologia e Direito - o presente texto também aborda sobre a sua origem e evolução histórica, os diferentes tipos de jornada noturna, suas características, efeitos jurídicos e restrições. De fato, o trabalho noturno merece atenção pois provoca no indivíduo agressão física e psicológica intensas, por supor o máximo de dedicação de suas forças físicas e mentais em período em que o ambiente físico externo induz ao repouso. Somado a isso, ele também tende a agredir, com substantiva intensidade, a inserção pessoal, familiar e social do indivíduo nas micro e macrocomunidades em que convive. São de extrema importância, as razões pelas quais o direito do trabalho brasileiro sempre tendeu a conferir tratamento diferenciado ao trabalho noturno, em contrapartida ao trabalho realizado durante o dia.

Palavras chave: Jornada de Trabalho. Adicional Noturno. Horas Noturnas.

\begin{abstract}
The working hours, topic which this magazine approaches, can be characterized as the daily period (day or night) which the worker is available - subordinated to your employer. Within this branch of study of labor law, there is a workday night theme of this article, which takes into account the period of employment works during the night, specifically determined by law, and its consequences within the national legal system. In order to monitor the intense academic study of the nocturnal journey through the fields of the humanities and social sciences - anthropology, sociology, psychology and law - this article also discusses about its origin and historical evolution, the different types of working hours during the night, their characteristics, legal effects and restrictions. In fact, night work deserves attention because it causes intense physical and psychological aggression on people, by supposing the utmost dedication to their physical and mental forces in the period in which the external environment induces rest. Added to this, it also tends to attack with substantial intensity, personal, family and social integration of the individual in micro and macro communities that coexists. The reasons why the Brazilian labor law has always tended to give different treatment to night journeys of work, in contrast to the work done during the day, are extremely important.
\end{abstract}

Keywords: Working Hours. Night Additional. Night Work.

\footnotetext{
a Advogado. Bacharel em Direito pela PUCRS. Licenciado em História pela PUCRS. < diclima@hotmail.com>.

${ }^{\text {b }}$ Bacharelando em Direito pela PUCRS e Políticas Públicas pela UFRGS. <jonathanvargasfigueiredo@hotmail.com>.
} 


\section{INTRODUÇÃO}

As jornadas noturnas, biologicamente e socialmente, são mais pungentes ao ser humano do que as jornadas de trabalho exercidas durante o dia. $\mathrm{O}$ trabalho noturno - como o próprio nome refere, ocorrido durante a noite - ocasiona maior desgaste físico e mental do que a atividade laboral prestada no horário diurno, exigindo maior empenho e energia que, em consequência, ocasionam maior fadiga. Esta, por sua vez, pode acarretar na diminuição do rendimento profissional e aumentar o risco de acidentes de trabalho. Conjuntamente, gera prejuízos de ordem social e familiar uma vez que o labor noturno, o período de descanso e os hábitos da vida social não se harmonizam.

$\mathrm{Na}$ tentativa de compensar tais desgastes aos trabalhadores, o ordenamento jurídico brasileiro, através da Constituição Federal e da Consolidação das Leis do Trabalho estabelecem que a remuneração do trabalho noturno deva ser superior à do diurno. Tendo em vista que o trabalho realizado durante o período noturno é de grande importância, sendo de grande necessidade para diversos setores da economia, existe a reflexão de que não há como negá-lo ou proibi-lo, mas sim regulamentá-lo. De qual forma?

A Legislação Trabalhista estabeleceu dois fatores principais para equilibrar os prejuízos que o trabalho noturno pode causar ao empregado: o fator econômico (pagamento do adicional) e fator ergonômico (a redução da hora noturna em relação à hora diurna).

O presente artigo visa tratar de um tema tão relevante para o Direito do Trabalho, qual seja a jornada de trabalho noturna nas suas diferentes abordagens.

\section{EVOLUÇÃO}

O tema de horário noturno não se restringe somente a legislação pátria. É tratado internacionalmente pela Convenção no 171 da OIT.

Basicamente, o trabalho noturno é executado no período da noite. As legislações de outros países não são unânimes ao apontar o horário do período, como expões Sérgio Pinto Martins:

$\mathrm{Na}$ Espanha, considera-se noturno o horário das 22 às $6 \mathrm{~h} 00$ (Estatuto de los Trabajadores, art. 34.6); na Alemanha, das 20 às 6h00; em Portugal, das 22 às 7h00 (art. 192, 3, do Código do Trabalho); na França e na Itália, das 22 às 5h00; na Argentina, das 21 às 6 h00 (Ley de Contrato de Trabajo, art. 200). ${ }^{1}$

No Brasil, considera-se horário noturno para trabalhadores urbanos das 22:00 de um dia as 5:00 do outro ( $§ 2^{\circ}$, art. 73, CLT).
Um dos efeitos do labor noturno é o seu respectivo adicional, que no Brasil advêm da constituição de 1937, conforme conta o Autor:

A primeira determinação constitucional sobre o trabalho noturno foi a da Constituição de 1937, prevendo que o 'trabalho à noite, a não ser nos casos em que é efetuado periodicamente por turnos, será retribuído com remuneração superior ao diurno' (art. 137, j). A constituição de 1946 não fez mais distinção em razão de turnos, apenas dizendo: 'salário do trabalho noturno superior ao diurno' (art. 157, III) A constituição de 1967 repete a mesma disposição da Norma Ápice (art. 158, IV). O mesmo faz a EC no 1, de 1969 (art. 165, IV). ${ }^{2}$

Este regramento da Carta Magna permaneceu com o advento da Constituição de 1988, no seu artigo 7ํ․

Art. $7^{\circ}$ São direitos dos trabalhadores urbanos e rurais, além de outros que visem à melhoria da condição social:

$[\ldots]$

IX - remuneração do trabalho noturno superior à do diurno. ${ }^{3}$

Neste sentido, a Constituição de 1988 corroborou com o entendimento do diploma anterior, bem como da própria Consolidação das Leis do Trabalho, de 1947, onde há regramento específico sobre o tema da jornada noturna para o trabalhador urbano, em seu artigo $73^{4}$.

Posteriormente, visando abranger também os trabalhadores rurais, a Lei 5.889/73 estabeleceu os parâmetros para computar a jornada noturna, em atividades de pecuária e lavoura.

Por fim, diante da constante evolução das atividades laborais, o Direito do Trabalho ainda enquadrou outras atividades como os portuários, petroleiros e advogados.

\section{CARACTERÍSTICAS}

A prestação do labor noturno é mais desgastante para o trabalhador, no que tange aos fatores biológicos, familiar e social. Assim, o legislador, sob a égide do principio da proteção, que rege o Direito do Trabalho, tendeu a conferir um tratamento diferenciado para o trabalho prestado no período noturno.

Conforme preconiza Maurício Godinho Delgado:

[...] Esse tratamento diferenciado abrange, regra geral duas dimensões: de um lado, um conjunto de restrições à própria prestação do trabalho no turno da noite (de que é exemplo mais expressivo a vedação do labor noturno de menores de 18 anos). De outro lado, o favorecimento compensatório no 
cálculo da jornada noturna (através da redução ficta da hora noturna, por exemplo) e/ou favorecimento compensatório no cálculo da própria remuneração devida àquele que labora à noite (mediante o pagamento de um adicional específico, por exemplo). ${ }^{5}$

Demonstrando a preocupação da comunidade internacional com o advento do trabalho noturno, a OIT adotou, em junho de 1990, a Convenção no 171, que trata especificamente do labor à noite. Assim, Alice Monteiro de Barros traz a baila o conceito da jornada noturna expresso na convenção n. 171 da OIT, a qual foi ratificada pelo Brasil em 2003:

Considera-se trabalho noturno a atividade que exija a realização de serviços à noite, por um período de pelo menos sete horas consecutivas, compreendidas entre a meia-noite e às 5 horas da manhã, a ser determinada pela autoridade competente, mediante consulta prévia aos representantes de empregadores e trabalhadores ou por meio de convenções coletivas (art. $1^{\circ},{ }^{\circ} a$ '). ${ }^{6}$

Contudo, para compreender corretamente a razão destes pressupostos legais, devemos levar em conta o tratamento que o Direito do Trabalho dispensa a conceituação de jornada noturna, "tendendo a restringir o conceito de noite, de modo a não abranger, integralmente, todo o lapso temporal em que a luz solar se esconda abaixo do horizonte". Portanto, em primeiro lugar, visa encontrar um parâmetro imutável, em relação as condições climáticas, ao longo do ano. Ainda, há a problemática de os intensos desgastes provenientes do trabalho noturno, não apresentem a mesma intensidade, nas diversas fases da noite. Por fim, por razões econômicas, como mecanismo voltado a não encarecer o preço da força de trabalho contratada em toda a extensão do real trabalho noturno.

\section{FORMAS USUAIS}

O direito pátrio estabelece diferenças marcantes a delimitação da jornada noturna entre trabalhadores urbanos e rurais.

Normatizada pelo artigo 73 da Consolidação das Leis do Trabalho (CLT), a jornada noturna dos trabalhadores urbanos apresentam algumas características marcantes. Em primeiro lugar, a norma estabelece, no $\S 3^{\circ}$ do artigo 73 , que a hora noturna está restrita ao lapso temporal que vai das 22:00 de um dia, as 05:00 do dia seguinte, ou seja, 7 horas no total. Todavia, juridicamente esta jornada equivale a 8 horas trabalhadas. Isto ocorre porque a CLT considera a hora noturna menor que a hora diurna, isto é, 1 hora noturna equivale a 52’30”' e não a 60' (art. 73, § 1ํ). É denominada como hora ficta.

Em contrapartida, a jornada noturna estabelecida pela Lei $5.889 / 73$, em seu artigo $7^{\circ}$, não prevê a chamada hora ficta e estabelece horários diferentes para o cálculo da hora noturna. Para as atividades de lavoura, a jornada noturna é computada pelo período das 21:00 de um dia até 05:00 do outro. Já para as atividades de pecuária, o período compreendido é de 20:00 de um dia até 04:00 do outro. Portanto, ambos os casos a jornada real é de 8 horas, o que se deferência da jornada noturna urbana.

No mesmo sentido, a jornada dos portuários, estabelecida pela Lei $4.860 / 65^{8}$, estabelece a jornada noturna desta categoria das 19:00 às 07:00, ou seja, ainda mais favorável.

Estas discrepâncias entre o cálculo da jornada noturna, como dito, não leva só em conta a ausência de luz solar, mas sim as características específicas de cada atividade.

\section{EFEITOS JURÍDICOS}

O Direito do Trabalho consolida seu entendimento quanto à jornada noturna em dois pontos: o primeiro é quanto à restrição da prestação do trabalho prestado à noite, como veremos adiante; o segundo, diz respeito a compensação derivada desta prestação, ou seja, suas vantagens jurídicas. Este ponto em especial comporta os chamados efeitos jurídicos da jornada noturna.

Primeiramente, como já observado, o labor prestado à noite sofre uma diferenciação normativa, em relação aos trabalhadores rurais e urbanos. No mesmo sentido, há regramentos específicos para categorias como portuários, trabalhadores vinculados à atividade petrolífera e mesmo advogados, que são regidos pelo estatuto da OAB. Ainda, esses efeitos também são observados em situação específicas de trabalho, como no caso dos turnos ininterruptos.

No que diz respeito ao labor noturno de trabalhadores urbanos, Maurício Godinho Delgado ensina:

O trabalho noturno urbano recebe o duplo efeito da ordem jurídica: no tocante à própria extensão da jornada e no tocante à remuneração do período laborado ou à disposição. No tocante à extensão da jornada, sabe-se que a CLT instituiu a denominada hora ficta noturna, composta de 52 minutos e 30 segundo como medida componente da jornada noturna urbana. Esta regência especial, instituidora da hora noturna reduzida, já produz uma consequente sobrerremuneração sobre o efetivo período noturno trabalhado, em comparação a idêntico período durante o dia. ${ }^{9}$ 
Ou seja, só a constituição da hora ficta estabelecida na jornada noturna urbana já gera uma vantagem compensatória em relação à remuneração da hora diurna. O Autor ainda segue argumentando:

\begin{abstract}
[...] Ao lado dessa sobrerremuneração indireta, a oredem jurídica prevê, ainda, uma sobrerremuneração direta e distintiva, consubstanciada em um adicional incidente sobre cada hora ficta ou fração laborada à noite. Esse adicional noturno é de $20 \%$ sobre o valor da horas ou fração trabalhada (art. 73, caput, CLT). ${ }^{10}$
\end{abstract}

Assim, conforme entendimento do Autor acontece o duplo efeito jurídico sobre a remuneração da jornada noturna urbana.

O labor prestado á noite pelo trabalhador rural recebe um efeito mais brando da ordem jurídica. A Lei 5.889/73, que trata do rurícola, não prevê a chamada hora ficta. Isto é, a hora computada do labor noturno, tanto em atividades de lavoura como pecuária, tem duração de 60 minutos. Todavia, com objetivo de compensar a ausência de hora ficta, o legislador estabeleceu que o adicional noturno urbano seria de $25 \%$ de acréscimo sobre a remuneração normal, e não de $20 \%$ como estabelecido na jornada noturna urbana.

Conforme Maurício Godinho Delgado,

O trabalho noturno portuário recebe também efeito singelo da ordem jurídica (Lei no 4.860/63; art. 73, caput, CLT; OJ 60, SDI-I/TST): não se prevê a hora ficta, mas simples adicional de 20\%. Em compensação, a extensão da jornada noturna é bastante favorável (de 19:00 às 7:00), respeitadas, é claro, as durações-padrão constitucionais (oito horas ao dia ou, pelo menos, 44 semanais). ${ }^{11}$

\section{No mesmo sentido, corrobora a jurisprudência atual:}

ADICIONAL NOTURNO. TRABALHADOR PORTUÁRIO. Nos termos da norma coletiva, é noturno o trabalho do trabalhador portuário prestado entre as $19 \mathrm{~h} 30 \mathrm{~min}$ e as $7 \mathrm{~h}$. Contudo, o artigo $4^{\mathrm{O}} \mathrm{da}$ Lei $n^{\circ}$ 4.860/65 estabelece horário noturno mais benéfico para o trabalhador portuário (a partir das 19h), razão pela qual deve prevalecer sobre o disposto na norma coletiva. Diante disso, é devido o pagamento de diferenças de adicional noturno pela consideração do horário noturno previsto no artigo $4^{\circ}$ da Lei $\mathrm{n}^{\mathrm{O}} 4.860 / 65$. Apelo do reclamante provido. (Processo no 0001002-11.2011.5.04.0122 RO, disponível em www.trt4.jus.br, acesso em 28/02/2014).
O labor noturno na área petrolífera é regido pela Lei $5.811 / 72$. Esta lei regulamenta as atividades vinculadas a exploração, perfuração e refinação de petróleo, industrializados do xisto, indústria petroquímica e transporte de petróleo e seus derivados por meio de dutos (art. 1ํㅡ, Lei 5.811/72). Este diploma estabelece somente a sobrerremuneração decorrente do adicional noturno, à título de $20 \%$ sobre o salário normal.

A atividade do advogado também é regulada por lei especial. Como dita Sérgio Pinto Martins:

Para o advogado na há redução da hora noturna. Considera-se como período noturno das 20 às $5 \mathrm{~h} 00$. $\mathrm{O}$ adicional noturno será de $25 \%$. Por ser maior o adicional, há compensação pela inexistência da hora reduzida. Por se tratar de lei especial que regula o tema (Lei n⿳o 8.906/94, art. $2^{\circ}$, $\S 3^{\circ}$ ), não se observa a CLT. É o mesmo caso do trabalhador rural. ${ }^{12}$

No que se refere a turnos ininterruptos de revezamento, o caput do artigo 73 da CLT determina que nos casos de revezamento semanal ou quinzenal o adicional noturno não é devido. Contudo, essa disposição foi revogada desde a Constituição Federal de 1946, tornando-se norma inconstitucional. O STF, por meio da Súmula 213, decidiu que "é devido o adicional de serviço noturno ainda que sujeito o empregado ao regime de revezamento".

Importante referir que, da mesma maneira, na jornada chamada de $12 \times 36$ permanece imperativo o dispositivo constitucional contido no inciso IX do art. 7ํㅡㄹ da CF88, sendo devido aos trabalhadores alocados neste regime o referido adicional.

O artigo 73, $3^{\circ}$, ainda traz outra exceção a regra, qual seja do trabalho noturno decorrente da natureza da atividade da empresa. Da mesma forma, após o advento da norma constitucional de 88, e das Súmulas 213 e 214 do STF, bem como o antigo enunciado 130 do TST, é inconstitucional a diferenciação feita pelo $\S 3^{\circ}$, sendo devido o respectivo adicional e computada a hora ficta para trabalhadores urbanos.

Há ainda a questão do chamado horário misto e da prorrogação laborativa após a prestação do labor noturno, contidas nos parágrafos $4^{\circ}$ e $5^{\circ}$ do artigo 73 da CLT, respectivamente. Segundo Alice Monteiro de Barros,

Cumprida integralmente a jornada no período noturno e prorrogada esta, devido é também o adicional quanto às horas prorrogadas, conforme exegese do art. 73, $\S 5^{\circ}$, da CLT (Súmula no 60 do TST). Evidentemente, a concessão do adicional noturno, neste caso, justifica-se, porque a prorrogação da jornada após o cumprimento do horário noturno implica em maior desgaste físico e psíquico para o trabalhador. $\mathrm{O}$ mesmo não ocorre se as horas antecederem o período noturno. ${ }^{13}$ 
Mesmo entendimento nos dá Sérgio Pinto Martins:

É necessário, portanto, conjugarem-se as disposições contidas nos $\S \S 4^{\circ}$ e $5^{\circ}$ do art. 73 da CLT para se obter uma interpretação lógica da lei. No horário misto realizado das 21 às $5 \mathrm{~h} 00$, o período das 21 às $22 \mathrm{~h} 00$ não teria adicional noturno ou hora reduzida porque não é realizado no espaço de tempo considerado pela lei como hora noturna. ${ }^{14}$

Porém, segundo o Autor, se a jornada fosse estendida até as 6:00, o período compreendido pelo espaço das 5:00 às 6:00, estaria compreendido pelo $\S 5$ o do artigo 73 da CLT, sendo devido o adicional pela prorrogação.

Por fim, importante referir que se o adicional noturno for pago com habitualidade, integrará o salário do trabalhador para todos os efeitos, como férias, $13^{\text {o }}$ salário, aviso prévio indenizado, DSRs, FGTS, conforme disposto na súmula 60 , I, do TST.

\section{RESTRIÇÕES}

A ordem jurídica pátria estabeleceu restrições ao trabalho noturno, de alguns grupos, em razão dos desgastes físicos e psicossociais que poderiam ser causados pelo exercício dessa prática.

Segundo Maurício Godinho Delgado “A vedação ao trabalho noturno dos menores é plena, no Direito brasileiro. A Constituição a enfatiza (art. 7ํ, XXXIII, $\mathrm{CF} / 88$ ) embora já constasse dos textos legais anteriores a 1988 (art. 404, CLT; art. 8ㅇ, Lei no 5.889/73)." ${ }^{15}$

No mesmo sentido Orlando Gomes e Elson Gottschalk preconizam:

A Constituição de 1988 proíbe o trabalho noturno, perigoso ou insalubre, aos menores de dezoito anos e de qualquer trabalho a menores de quatorze anos, salvo aprendiz, mas protege o mercado de trabalho à mulher mediante incentivos específicos, que bem pode compreender o trabalho noturno (art. 7으. XX e XXXIII). ${ }^{16}$

Há também, conforme a CLT à restrição do trabalho noturno da mulher, observados nos Artigos 379 e 380. Porém, verifica-se ai um ponto controverso. Ocorre que, com o advento da Constituição de 1988, em seu artigo $5^{\circ}$, caput, e inciso I; e artigo 7º, XX, os dispositivos da lei ordinária entrariam em confronto com a Norma Magna, visto que se enquadrariam como atos discriminatórios.

Posteriormente estes Artigos foram revogados com o advento da Lei $\mathrm{n}^{\mathrm{O}}$ 7.855/89.

No segmento bancário, regra geral, o labor noturno é proibido, conforme o artigo $224^{17}, \S 11^{\circ}$, CLT. Todavia, a própria CLT estabelece algumas exceções a essa regra. É o caso dos “"...] trabalhadores que exercem cargos de gerência, direção, fiscalização, chefia e equivalentes ou outros cargos de confiança, desde que observada a percepção de gratificação não inferior a $1 / 3$ do salário de cargo efetivo ( $\$ 2^{\circ}$ do art. 244, CLT)". ${ }^{18}$

Ainda, há exceções quantos aos trabalhadores com tarefas de compensação de cheques ou à computação eletrônica (art. $1^{\circ}$, caput, DL n⿳ํㅗ 546/6919)

\section{CONCLUSÃO}

Em razão do trabalho noturno, uma boa parte do dia deve ser reservada ao repouso, perturbando a vida social do trabalhador ao provocar o desencontro de seus membros e dificultando a convivência familiar. Do ponto de vista médico é pacífico o entendimento de que a jornada de trabalho realizada no período noturno deve ser formal e genericamente proibida, uma vez que é extremamente prejudicial à saúde do trabalhador. Entretanto, não obstante a prejudicialidade do trabalho noturno ao bem-estar e à saúde do trabalhador, há situações em que o mesmo é inevitável, como ocorre nos serviços de utilidade pública ou nas indústrias que funcionam diuturnamente, tornando impossível seja genericamente proibido. Dessa forma, justificam-se as restrições aos menores de idade, protegidos legalmente pela fragilidade da maturidade ainda em formação.

Ao passo que a sociedade evolui, de maneira globalizada, estamos cada vez mais afastados da possibilidade de negação da atividade laboral noturna, contudo, medidas significativas, não somente através da redução da hora ficta ou da majoração dos salários através do adicional podem ser tomadas. Dentre elas, parece ser fundamental a adoção de políticas de prevenção contra os possíveis distúrbios à saúde do trabalhador por parte do governo, um maior rigor legislativo no aperfeiçoamento da organização dos turnos, e a inclusão, no processo de seleção de recursos humanos por parte das empresas, de critérios para a admissão de trabalhadores que consigam compor um perfil mais adaptável às condições do trabalho noturno.

Sem dúvida alguma, existe a necessidade contínua de estudos sobre o tema, afim de adequar e viabilizar o emprego de novos conhecimentos deste fenômeno nos casos práticos, nos métodos e técnicas de trabalho da vida cotidiana de empregados e empregadores. Acima de tudo, a busca incessante de alternativas para garantir as melhores condições de trabalho - de qualidade de vida - do trabalhador, no sentido de preservar sua saúde física e mental, bem como o de sua família, deve ser prioridade no campo jurídico-acadêmico. 


\section{REFERÊNCIAS}

BARROS, Alice Monteiro de. Curso de Direito do Trabalho. São Paulo: LTr, 2009.

CAHALI, Yussef Said (Org.). Código Civil, Código de Processo Civil, Código Comercial, Constituição Federal, Legislação civil, processual civil e empresarial. São Paulo: RT, 2011.
DELGADO, Maurício Godinho. Curso de Direito do Trabalho. 12. ed. São Paulo: LTr, 2013.

GOMES, Orlando e GOTTSCHALK, Elson. Curso de Direito do Trabalho. Rio de Janeiro: Forense, 2003.

MARTINS, Sérgio Pinto. Direito do Trabalho. São Paulo: Atlas, 2008.

\section{NOTAS}

1 MARTINS, Sérgio Pinto. Direito do Trabalho. 24. ed. São Paulo: Atlas, 2008, p. 517.

2 Ibidem

3 CAHAli, Yussef Said (Org.). Código Civil, Código de Processo Civil, Código Comercial, Constituição Federal, Legislação civil, processual civil e empresarial. São Paulo: RT, 2011.

4 Art. 73. Salvo nos casos de revezamento semanal ou quinzenal, o trabalho noturno terá remuneração superior a do diurno e, para esse efeito, sua remuneração terá um acréscimo de $20 \%$ (vinte por cento), pelo menos, sobre a hora diurna.

$\S 1$ 을 A hora do trabalho noturno será computada como de 52 minutos e 30 segundos. $\S 2^{\circ}$ Considera-se noturno, para os efeitos deste artigo, o trabalho executado entre as 22 horas de um dia e as 5 horas do dia seguinte. $\S 3^{\circ} \mathrm{O}$ acréscimo, a que se refere o presente artigo, em se tratando de empresas que não mantêm, pela natureza de suas atividades, trabalho noturno habitual, será feito, tendo em vista os quantitativos pagos por trabalhos diurnos de natureza semelhante. Em relação às empresas cujo trabalho noturno decorra da natureza de suas atividades, o aumento sera calculado sobre o salário mínimo geral vigente na região, não sendo devido quando exceder desse limite, já acrescido da percentagem. $\S 4^{\circ}$ Nos horários mistos, assim entendidos os que abrangem períodos diurnos e noturnos, aplica-se às horas de trabalho noturno o disposto neste artigo e seus parágrafos.

$\S 5^{\circ}$ Às prorrogações do trabalho noturno aplica-se o disposto neste capítulo.

5 DELGADO, Maurício Godinho. Curso de Direito do Trabalho. 12. ed. São Paulo: LTr, 2013, p. 956.

6 BARROS, Alice Monteiro de. Curso de Direito do Trabalho. 5. ed. São Paulo: LTr, 2009, p. 690.

7 Art. 7o Para os efeitos desta Lei, considera-se trabalho noturno o executado entre as vinte e uma horas de um dia e as cinco horas do dia seguinte, na lavoura, e entre as vinte horas de um dia e as quatro horas do dia seguinte, na atividade pecuária.
Parágrafo único. Todo trabalho noturno será acrescido de $25 \%$ (vinte e cinco por cento) sobre a remuneração normal.

8 Art $4^{\circ} \ldots$

$\S 1^{\circ}$ Os períodos de serviço serão diurno, entre 7 (sete) e 19 (dezenove) horas, e noturno, entre 19 (dezenove) e 7 (sete) horas do dia seguinte, ... VETADO ... A hora do trabalho... VETADO... é de 60 (sessenta) minutos ... VETADO ...

9 DELGADO, Maurício Godinho. Op. cit., p. 958.

${ }^{10}$ Ibidem.

${ }^{11}$ Ibidem.

12 MARTINS, Sérgio Pinto. Op. cit., p. 519.

${ }^{13}$ BARROS, Alice Monteiro de. Op. cit., p. 686

${ }_{14}$ MARTINS, Sérgio Pinto. Op. cit., p. 522.

${ }^{15}$ DELGADO, Maurício Godinho. Op. cit., p. 960.

${ }^{16}$ GOMES, Orlando e GOTTSCHALK, Elson. Curso de Direito do Trabalho. 16. ed. Rio de Janeiro: Forense, 2003, p. 292.

17 Art. 224. A duração normal do trabalho dos empregados em bancos, casas bancárias e Caixa Econômica Federal será de 6 (seis) horas continuas nos dias úteis, com exceção dos sábados, perfazendo um total de 30 (trinta) horas de trabalho por semana.

$\S 1^{\circ}$ A duração normal do trabalho estabelecida neste artigo ficará compreendida entre 7 (sete) e 22 (vinte e duas) horas, assegurando-se ao empregado, no horário diário, um intervalo de 15 (quinze) minutos para alimentação.

$\S 2^{\mathrm{O}}$ As disposições deste artigo não se aplicam aos que exercem funções de direção, gerência, fiscalização, chefia e equivalentes, ou que desempenhem outros cargos de confiança, desde que o valor da gratificação não seja inferior a $1 / 3$ (um terço) do salário do cargo efetivo.

${ }^{18}$ DELGADO, Maurício Godinho. Op. cit., p. 960.

19 Art. $1^{\text {o }}$ É permitido, inclusive à mulher, o trabalho noturno em estabelecimento bancário, para a execução de tarefa pertinente ao movimento de compensação de cheques ou a computação eletrônica, respeitado o disposto no artigo 73, e seus parágrafos da Consolidação das Leis do Trabalho. 